\title{
A further investigation of skin-test responsiveness and suppression in leprosy patients and healthy school children in Nepal
}

\author{
ALISON MORTON,* PAMELA NYE, †§ \\ G A W ROOK, $\dagger$ N SAMUEL $\ddagger \&$ J L STANFORD $†$ \\ * Middlesex Hospital Medical School, London; † School of Patho- \\ logy, Middlesex Hospital Medical School, London WIP 7LD; \\ $\ddagger$ Anandaban Leprosy Hospital, P.O. Box 151, Kathmandu, \\ Nepal
}

\section{Accepted for publication 16 January 1984}

\begin{abstract}
Summary This paper confirms and extends our previous studies of skin-test responsiveness and suppression in Nepal. The ability of leprosy patients to make positive responses to group i and group ii (common mycobacterial, and slow grower associated) antigens is markedly impaired in comparison with healthy school children. Of the 2 suppressor mechanisms associated with mixtures of reagents prepared from fast and slow growers which were demonstrated in Bombay, only the phenomenon of local suppression previously seen in Nepal was found. Although originally thought to be associated with group iv (species specific) antigens of fast growers, the phenomenon occurred whichever reagent of 9 fast growing species was mixed with the slow grower reagent. Thus our present view is that the phenomenon demonstrable in both Bombay and Nepal is related to the presence of antigen common to any fast growing species. The observation of this suppressor mechanism in leprosy patients, leprosarium staff and healthy school children shows that it is unlikely to be related to the disease, although it may be related to susceptibility to it.

Our inability to demonstrate in Nepal the distant suppressor mechanism found in Bombay suggests that this may be due to geographical differences, probably in the amount of oral contact with environmental mycobacteria, and perhaps in the species that are present.
\end{abstract}

\section{Introduction}

A system of quadruple skin-testing employing 3 mixtures of new tuberculins ${ }^{1}$ and Burulin, ${ }^{2}$ prepared from Mycobacterium ulcerans, was designed for the investiga-

$\S$ Address for reprints: School of Pathology, Middlesex Hospital Medical School, London. 
tion of responsiveness of leprosy patients to different groups of mycobacterial antigens. Burulin was used since M. ulcerans is not known to occur in Nepal and positive responses to it must be to the group i or ii antigens shared with other species. Preliminary studies ${ }^{3}$ showed marked impairment of the ability to respond to groups i and $\mathrm{ii}^{4}$ antigens and uncovered an unexpected suppressor mechanism. This was local suppression of response to the antigens of slowly growing mycobacteria when these were injected as a mixture with the antigens of fast growing species. Further investigation of this with modified reagents 5 in Bombay confirmed this type of suppression and showed it to be associated with the species M. duvalii, M. fortuitum, M. flavescens, M. gilvum, M. neoaurum and $M$. nonchromogenicum. A second suppressor phenomenon was observed in Bombay, when antigens of the fast growing species $M$. chitae, $M$. diernhoferi, $M$. rhodesiae and $M$. vaccae were injected with the mixed antigens of slowly growing species. In this phenomenon the suppression was not expressed locally, but distantly on the other arm where the mixed antigens of slowly growing species had been injected on their own.

In addition to the above, previous studies ${ }^{3,5,6}$ have shown that a system of quadruple skin-testing with individual new tuberculins distinguishes 3 categories of responders dependent upon whether the person tested responds to all 4 reagents (category 1), none of the reagents (category 2), or some but not all of the reagents (category 3 ). That these differences have significance is shown by categories 1 and 2 including more individuals than would be expected by chance and by the observation that category 2 individuals lack the HLA-DR3 determinant. ${ }^{7}$ Previous studies (largely unpublished) have shown that category 1 is reduced in the course of tuberculosis and leprosy and that category 2 is expanded in parts of the leprosy spectrum. ${ }^{6}$

This student elective study was carried out to further investigate responsiveness to antigen groups and to try to relate suppressor mechanisms operative in Nepal to particular mycobacterial species.

\section{Materials and methods}

The persons tested were 95 children aged 5-17 years (mean age 12.5 years), of which 53 were male, attending the Himalayan Middle School, Banepa, and 69 leprosy patients with a mean age of 37.2 years (56 were male) at Anandaban Leprosy Hospital. Sixteen of the patients had lepromatous disease, 19 had borderline lepromatous disease, 29 had borderline tuberculoid disease and $5 \mathrm{had}$ tuberculoid disease. All the leprosy patients were receiving chemotherapy, which in the case of multibacillary disease included rifampicin.

The reagents were the same as those used in our previous studies ${ }^{3,5}$ except that the mixed reagent prepared from 12 fast growers and 12 slow growers $(\mathrm{F} / \mathrm{S})$ was not used at all, and the combinations of the mixed slow grower reagent (SG) with 
Duvalin and Nonchromogenicin used in Bombay were replaced with combinations of SG with $\mathrm{R} 877 \mathrm{~S}$ (a reagent prepared from the smooth variant of $M$. vaccae strain R877), and with Smegmatin (prepared from M. smegmatis). These reagents are listed in Table 1.

Each individual was tested with SG and the mixed fast grower reagent (FG) on one arm and with Burulin and the variable 4th reagent on the other arm. So far as possible an equal number of school children received each of the different fourth reagents. Only 6 of the SG and fast grower mixes were tested on the leprosy patients because of the small number available. As usual responses were recorded as diameters of induration $72 \mathrm{~h}$ after injection.

\section{Results}

The distribution of the categories of responders according to the reagents they received are shown in Table 2 and these data are also incorporated in the figure. Twenty-five of the 95 school children and one of the 69 leprosy patients (a BT case) were category 1 responders reacting to all 4 reagents. Fifteen school children and 32 leprosy patients ( $2 \mathrm{TT}, 8 \mathrm{BT}, 13 \mathrm{BL}$ and $9 \mathrm{LL}$ ) were of category 2, failing to respond to any of the reagents with which they were tested.

The responses of individual category 3 school children are given in Table 3a

Table 1. Reagents tested on everyone

$\begin{array}{ll}\text { FG } & \text { Contains antigens of } 12 \text { different fast growing mycobacteria } \\ \text { SG } & \text { Contains antigens of } 12 \text { different slow growing mycobacteria } \\ \text { B } & \text { Burulin prepared from M. ulcerans }\end{array}$

Fourth reagents consisting of equal volumes of reagent SG with the following reagents prepared from fast growing species

\begin{tabular}{lll}
\hline $\mathrm{SG} / \mathrm{Chi}$ & $\mathrm{SG}+$ Chitin & $(M$. chitae $)$ \\
SG/Dh & SG + Diernhoferin & $(M$. diernhoferi $)$ \\
SG/F & SG + Flavescin & $(M$. favescens $)$ \\
SG/Gi* & SG + Gilvin & $(M$. gilvum $)$ \\
SG/Ne* & SG + Neoaurumin & $(M$. neoaurum $)$ \\
SG/R & SG + Ranin & $(M$. fortuitum $)$ \\
SG/Rh* & SG + Rhodesin & $(M$. rhodesiae $)$ \\
SG/Sm* & SG + Smegmatin & $(M$. smegmatis $)$ \\
SG/R877R & SG + Vaccin R & $(M$. vaccae strain R877 rough $)$ \\
SG/R877S & SG + Vaccin S & $(M$. vaccae strain R877 smooth $)$ \\
& &
\end{tabular}

* Only tested on school children. 
Table 2. Distribution of the categories of responders

\begin{tabular}{llcc}
\hline & \multicolumn{3}{c}{ Responder categories } \\
4th reagent & 1 & 2 & 3 \\
\hline School children & & & \\
$\quad$ SG/Chi & 5 & 1 & $3(1)^{*}$ \\
SG/Dh & 1 & 1 & 7 \\
SG/F & 3 & 2 & 4 \\
SG/Gi & $1(1)$ & 2 & $6(2)$ \\
SG/Ne & 1 & 3 & $6(1)$ \\
SG/R & 2 & 2 & $6(2)$ \\
SG/Rh & 2 & 1 & $7(2)$ \\
SG/Sm & 4 & 1 & $5(2)$ \\
SG/R877R & 5 & 1 & $4(1)$ \\
SG/R877S & 1 & 1 & 7 \\
\hline Totals & 25 & 15 & 55 \\
\hline & & & \\
\hline Leprosy patients & & & \\
SG/Chi & 0 & 10 & $10(5)$ \\
SG/Dh & 0 & 0 & $4(3)$ \\
SG/F & 0 & 7 & $6(4)$ \\
SG/R & 0 & 5 & 6 \\
SG/R877R & 1 & 4 & $6(3)$ \\
SG/R877S & 0 & 6 & $4(3)$ \\
\hline Totals & 1 & 32 & 36 \\
\hline
\end{tabular}

* Numbers in parentheses are those showing local suppression at the 4 th reagent site.

and those of the category 3 leprosy patients in Table $3 \mathrm{~b}$. Ten of the 55 category 3 children $(18 \%)$ and 18 of the 36 category 3 patients $(50 \%)$ showed suppression of response to the $\mathrm{SG} /$ fast grower mixtures, but this did not seem to be associated with any particular fast growing species. A reduction to half or less of the diameter of induration to SG alone is taken as evidence of suppression. One school child and 1 BT leprosy patient (marked ${ }^{* *}$ in the tables) may show suppression of response to SG of the kind seen in Bombay. Fifteen category 3 school children and 5 category 3 patients responded to Burulin; presumably to its group $\mathrm{ii}^{4}$ antigens. 


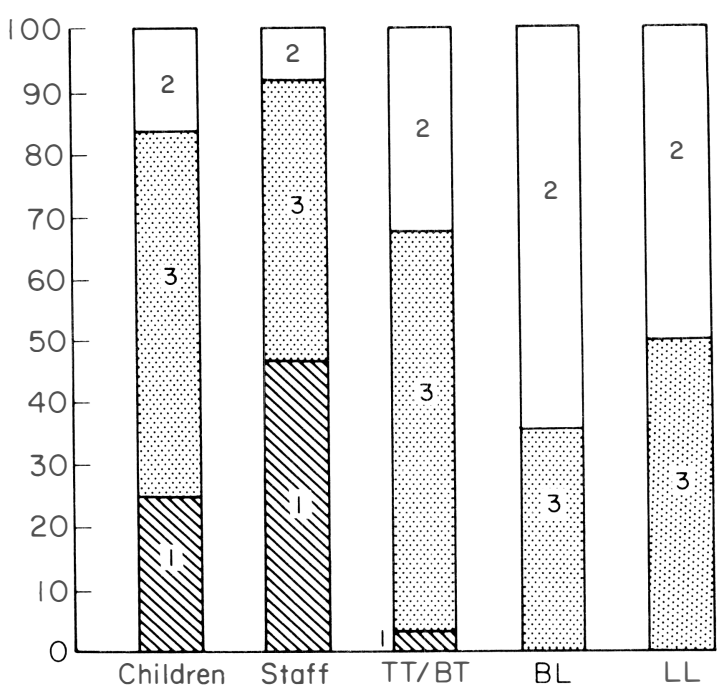

Figure 1. Division of the study groups into the categories of skin-test responsiveness. This figure includes data from the present study and an earlier study in Nepal. ${ }^{3}$

\section{Discussion}

This second study in Nepal confirms remarkably well the observation of our preliminary investigation. ${ }^{3}$ Only 2 out of the combined total of 133 leprosy patients tested in the 2 studies were category 1 responders possibly reacting to group i (common mycobacterial) antigens. Both were borderline tuberculoid patients. Responses to group ii (slow grower associated) antigens were restricted to 5 out of 33 patients of category 3 in the first study and to 5 out of 36 such patients in this second study. In comparison, 10 out of 12 category 3 staff members and 15 out of 55 category 3 school children produced positive responses to Burulin. Thus the results of this second study strongly support our earlier contention that leprosy patients do not produce positive skin-test responses to group i antigens and have an impaired ability to respond to group ii antigens. Recently published data on HLA-DR typing of leprosy patients ${ }^{8}$ and healthy persons in relation to their skin-test response categories ${ }^{7}$ suggests that perhaps there is a genetic basis for these observations.

None of the individuals included in the study had recently received other skin-tests, but most of the leprosy patients had been tested with other reagents in the past. However, there is no available evidence that this would have influenced our results. The patients with multibacillary disease were receiving drug regimens including rifampicin, and although this may have had some effect the distribution of responder categories in the present study was little different from that found in 
278 Alison Morton et al.

Table 3.

(a) Individual skin-test responses $(\mathrm{mm})$ in category 3 school children

\begin{tabular}{|c|c|c|c|c|c|c|c|}
\hline FG & SG & SG/Chi & B & FG & SG & $\mathrm{SG} / \mathrm{Dh}$ & B \\
\hline 0 & 9 & 8 & 0 & 8 & 15 & 13 & 0 \\
\hline 6 & 20 & 8 & 0 & 0 & 25 & 27 & 0 \\
\hline \multirow[t]{4}{*}{0} & 11 & 9 & 0 & 0 & 9 & 10 & 0 \\
\hline & & & & 0 & 15 & 15 & 10 \\
\hline & & $\mathrm{SG} / 877 \mathrm{R}$ & & 10 & 15 & 11 & 0 \\
\hline & & & & 6 & 24 & 23 & 0 \\
\hline 0 & 13 & 0 & 0 & 0 & 7 & 8 & 6 \\
\hline 10 & 15 & 10 & 0 & & & & \\
\hline 0 & 3 & 3 & 0 & & & $\mathrm{SG} / \mathrm{Gi}$ & \\
\hline \multirow[t]{4}{*}{0} & 13 & 9 & 5 & & & & \\
\hline & & & & 0 & 5 & 9 & 5 \\
\hline & & $\mathrm{SG} / \mathrm{R}$ & & 0 & 12 & 7 & 0 \\
\hline & & & & 0 & 0 & 7 & $5^{* *}$ \\
\hline 0 & 8 & 0 & 5 & 0 & 8 & 0 & 0 \\
\hline 0 & 16 & 10 & 15 & 0 & 13 & 11 & 6 \\
\hline 0 & 17 & 15 & 10 & 0 & 17 & 14 & 9 \\
\hline 0 & 10 & 10 & 0 & & & & \\
\hline 0 & 10 & 0 & 0 & & & $\mathrm{SG} / \mathrm{Rh}$ & \\
\hline \multirow[t]{4}{*}{0} & 7 & 5 & 0 & & & & \\
\hline & & & & 0 & 15 & 0 & 0 \\
\hline & & $\mathrm{SG} / \mathrm{F}$ & & 3 & 5 & 3 & 0 \\
\hline & & & & 0 & 5 & 0 & 0 \\
\hline 0 & 18 & 19 & 0 & 0 & 10 & 16 & 0 \\
\hline 0 & 4 & 4 & 0 & 0 & 3 & 5 & 0 \\
\hline 0 & 14 & 11 & 0 & 0 & 10 & 10 & 0 \\
\hline \multirow[t]{2}{*}{9} & 14 & 16 & 0 & 0 & 8 & 11 & 0 \\
\hline & & SG/R877S & & & & $\mathrm{SG} / \mathrm{Ne}$ & \\
\hline 0 & 14 & 19 & 0 & 0 & 17 & 12 & 0 \\
\hline 0 & 16 & 23 & 8 & 0 & 11 & 0 & 0 \\
\hline 0 & 23 & 16 & 10 & 0 & 10 & 14 & 6 \\
\hline 0 & 9 & 7 & 0 & 0 & 5 & 5 & 0 \\
\hline 9 & 0 & 0 & 0 & 0 & 15 & 14 & 0 \\
\hline 0 & 20 & 20 & 0 & 0 & 3 & 3 & 0 \\
\hline \multirow[t]{2}{*}{0} & 11 & 20 & 3 & & & & \\
\hline & & $\mathrm{SG} / \mathrm{Sm}$ & & & & & \\
\hline 0 & 8 & 0 & 0 & & & & \\
\hline 0 & 12 & 12 & 0 & & & & \\
\hline 0 & 11 & 17 & 0 & & & & \\
\hline 0 & 12 & 12 & 6 & & & & \\
\hline 0 & 5 & 0 & 0 & & & & \\
\hline
\end{tabular}


Table 3 - (cont.)

(b) Individual skin-test responses ( $\mathrm{mm}$ ) in category 3 leprosy patients

\begin{tabular}{|c|c|c|c|c|c|c|c|c|c|}
\hline & FG & SG & $\mathrm{SG} / \mathrm{Chi}$ & B & & FG & SG & $\mathrm{SG} / \mathrm{Chi}$ & B \\
\hline \multirow[t]{8}{*}{ TT } & 7 & 5 & 0 & 8 & BL & 0 & 10 & 6 & 6 \\
\hline & 8 & 8 & 6 & 0 & & 0 & 11 & 0 & 0 \\
\hline & & & & & & 0 & 10 & 10 & 0 \\
\hline & & & $\mathrm{SG} / \mathrm{F} 1$ & & & 0 & 9 & 0 & 0 \\
\hline & & & & & & 0 & 6 & 7 & 0 \\
\hline & 0 & 9 & 0 & 0 & & & & & \\
\hline & & & $\mathrm{SG} / \mathrm{Chi}$ & & & & & $\mathrm{SG} / \mathrm{R}$ & \\
\hline & & & & & & 0 & 8 & 5 & 0 \\
\hline \multirow[t]{26}{*}{ BT } & 0 & 6 & 0 & 0 & & & & & \\
\hline & 7 & 7 & 10 & 0 & & & & $\mathrm{SG} / \mathrm{Chi}$ & \\
\hline & & & SG/R877R & & LL & 0 & 14 & 0 & 5 \\
\hline & 0 & 7 & 7 & 0 & & & & SG/R877R & \\
\hline & 0 & 10 & 0 & 0 & & & & & \\
\hline & 0 & 10 & 0 & 0 & & 0 & 8 & 9 & 0 \\
\hline & 0 & 10 & 11 & 0 & & 0 & 10 & 0 & 0 \\
\hline & & & $\mathrm{SG} / \mathrm{R}$ & & & & & $\mathrm{SG} / \mathrm{R}$ & \\
\hline & 0 & 6 & 9 & 0 & & 0 & 18 & 13 & 0 \\
\hline & 0 & 7 & 9 & 0 & & & & & \\
\hline & 0 & 8 & 8 & 0 & & & & $\mathrm{SG} / \mathrm{F}$ & \\
\hline & 0 & 6 & 5 & 5 & & & & & \\
\hline & & & & & & 0 & 7 & 0 & 0 \\
\hline & & & $\mathrm{SG} / \mathrm{F}$ & & & & & SG/R877S & \\
\hline & 0 & 10 & 5 & 0 & & & & & \\
\hline & 0 & 12 & 0 & 0 & & 0 & 6 & 0 & 0 \\
\hline & 0 & 0 & 7 & $0 * *$ & & 10 & 6 & 0 & 0 \\
\hline & 0 & 10 & 7 & 0 & & & & & \\
\hline & & & SG/R877S & & & & & & \\
\hline & 0 & 6 & 0 & 0 & & & & & \\
\hline & 0 & 0 & 0 & 2 & & & & & \\
\hline & & & $\mathrm{SG} / \mathrm{Dh}$ & & & & & & \\
\hline & 0 & 9 & 9 & 0 & & & & & \\
\hline & 0 & 11 & 0 & 0 & & & & & \\
\hline & 4 & 9 & 4 & 0 & & & & & \\
\hline & 0 & 4 & 0 & 0 & & & & & \\
\hline
\end{tabular}


other populations of leprosy patients receiving dapsone alone (unpublished observations).

The immunosuppression expressed as a relative failure to respond to the combinations of reagents prepared from slow and fast growing mycobacteria when injected together was observed in 10 of the category 3 and 1 of the category 1 school children and in 18 of the 36 category 3 leprosy patients. In the previous Nepal study ${ }^{3}$ this phenomenon was observed in 3 of 12 category 3 staff members and 21 of 33 category 3 leprosy patients.

Since the combined study shows that the phenomenon occurs in school children without known close contact with leprosy, staff members of the leprosarium and leprosy patients of all parts of the immunopathological spectrum, it is difficult to see how it can be directly related to development of the disease. Nevertheless, suppression of this kind is twice as common amongst category 3 responders at all parts of the disease spectrum (TTBT: $51 \%$, BL: $69 \%$, LL: $53 \%)$ than it is amongst school children $(18 \%)$ or staff members $(25 \%)$.

Although our failure to attribute the phenomenon to the inclusion of any particular fast growing species is not absolute proof that further investigations with other species would fail to do so, the evidence now available suggests that the phenomenon is either due to changes in proportions of the different groups of antigens present or to a suppressor activity associated with the group i antigens of fast growers. The involvement of group iii (fast grower associated) antigens would seem to be ruled out since M.vaccae has not been shown to contain them. ${ }^{9}$

The most striking difference between the Nepal results and those obtained previously in Bombay 5 is the almost complete absence of the suppressor phenomenon in which the addition of reagents prepared from $M$. chitae, $M$. diernhoferi, $M$. rhodesiae and $M$. vaccae to SG administered on one arm, suppressed the response to SG alone on the other arm. Whereas in Bombay 14 of $21(67 \%)$ contacts of leprosy patients and 30 of $51(59 \%)$ leprosy patients themselves showed this phenomenon, only 2 individuals in the present study, 1 school child and 1 BT patient might show the phenomenon even though 21 school children and 24 leprosy patients of category 3 received reagents expected to exhibit the effect. Similarly in the earlier Nepal study only 2 people, a staff member and a lepromatous patient may have demonstrated the phenomenon. Thus this type of suppression associated apparently with species specific antigens of certain fast growing species appears to be geographically determined. Possible geographical factors are racial genetics and different patterns of immunologically effective contact with freeliving mycobacteria. Of these the latter would seem most likely and recent unpublished work on experimental animals might relate the phenomenon to a large oral intake of mycobacteria with food and water. Our study groups in both Nepal and Bombay were of very mixed ethnic origin, but obviously there was a bigger Mongolian influence on those in Nepal. Although we cannot exclude the possibility that differences in the ethnic mixtures have influenced our results, experience in other places makes this unlikely. 


\section{Acknowledgments}

We should like to thank the children of the Himalayan Middle School, Banepa and the patients and staff of Anandaban Leprosy Hospital for their assistance and participation in this study. Our thanks are also due to LEPRA and the Leprosy Mission, respectively for financial support and hospitality, without which this study could not have been carried out.

\section{References}

${ }^{1}$ Shield MJ, Stanford JL, Paul RC, Carswell JW. Multiple skin-testing of tuberculosis patients with a range of new tuberculins, and a comparison with leprosy and Mycobacterium ulcerans infection. $J$ Hyg, 1977; 78: 331.

${ }^{2}$ Stanford JL, Revill WDL, Gunthorpe WJ, Grange JM. The production and preliminary investigation of Burulin, a new skin-test reagent for Mycobacterium ulcerans infection. J Hyg, 1975; 74: 7.

${ }^{3}$ Stanford JL, Nye PM, Rook GAW, Samuel NM, Fairbank A. A preliminary investigation of the responsiveness or otherwise of patients and staff of a leprosy hospital to groups of shared or species specific antigens of mycobacteria. Lepr Rev, 1981; 52: 321.

${ }^{4}$ Stanford JL, Grange JM. The meaning and structure of species as applied to mycobacteria. Tubercle, 1974; 55: 143.

${ }^{5}$ Nye PM, Price JE, Revankar CR, Rook GAW, Stanford JL. The demonstration of two types of suppressor mechanism in leprosy patients and their contacts by quadruple skin-testing with mycobacterial reagent mixtures. Lepr Rev, 1983; 54: 9.

${ }^{6}$ Stanford JL. A mycobacteriologist's view of the immunology of leprosy. Bulletin de L'Institut Pasteur, 1981; 79: 261.

7 Eden W Van, De Vries RRP, Stanford JL, Rook GAW. HLA-DR3 associated genetic control of response to multiple skin-tests with new tuberculins. Clin Exp Imm, 1983; 52: 287-92.

8 Eden W Van, De Vries RRP, D'Amaro J, Schreuder GMTh, Leiker DL, Van Rood JJ. HLA-DR associated genetic control of the type of leprosy in population from Surinam. Human Imm, 1982; $4: 343$.

9 Stanford JL, Rook GAW, Convit J, Godal T, Kronvall G, Rees RJW, Walsh GP. Preliminary taxonomic studies on the leprosy bacillus. B J Exp Path, 1975; 56: 579. 